\title{
COMUNIDADES TRADICIONAIS: SABERES E SABORES DOS INDIGENAS DE ARATUBA AOS QUILOMBOLAS DE BATURITÉ- CE
}

\author{
Thayres Maciel, Magno de Sousa, Anna Érika Lima \\ Instituto Federal de Educação, Ciência e Tecnologia do Ceará - IFCE - Campus de Baturité \\ <thayresmaciel@gmail.com>, <alemagnodesousa@gmail.com>,<annaerika@ifce.edu.br>
}

DOI: 10.21439/conexoes.v10i3.869

\begin{abstract}
Resumo. As comunidades tradicionais são reconhecidas pelo seu modo de organização e cultura própria, por ter seus costumes, práticas, religião e reprodução social baseadas na ancestralidade e em suas tradições. Entre as existentes no território brasileiro e no Ceará, especificamente, tomamos como objeto de estudo a aldeia Kanindé de Aratuba onde vivem 185 famílias, cerca de 641 habitantes, e os Quilombolas da Serra do Evaristo localizado no Município de Baturité, onde residem atualmente 150 famílias, aproximadamente, 560 habitantes; ambas vivem, principalmente, da agricultura familiar, a qual é responsável pela sua principal fonte de alimentação. Nesse contexto, definimos o recorte espacial dessas comunidades pela sua historicidade e expressiva cultura alimentar, com o foco na identificação dos seus alimentos tradicionais, considerando seus saberes e costumes locais. Para consolidação desta pesquisa, foi fundamental o desenvolvimento de um estudo etnográfico, que nos possibilitou por meio de observação participativa efetivar o levantamento de dois pratos tradicionais da aldeia que foram o mungunzá salgado e o pirão de fava; e três no quilombo o mungunzá salgado, doce de mamão e a cocada, sendo que desses, dois possuem as mesmas características e modos de preparo diferente além de serem comumente consumidos em épocas festivas são reconhecidos como alimentos tradicionais pelas duas comunidades.
\end{abstract}

Palavras-chaves: Comunidades tradicionais. Tradição. Alimentos tradicionais. Indígenas. Quilombolas.

\begin{abstract}
Traditional communities are recognized for their organizational processes in Brazil and particularly its own and unique culture, to have their customs, practices, religion and social reproduction based on ancestry and tradition. Among all of the existing in Brazil and Ceará specifically, we take as the object of study Kanindé village Aratuba which live 185 families distributed around 641 inhabitants, and the Quilombo of Evaristo located in the city of Baturité, where 150 families currently reside subdivided into about 560 inhabitants; both live preferably from family farms, coming from the main power supply. We chose these communities for its historicity and expressive food culture, with a focus on identification of their traditional foods, considering their knowledge and local customs. To consolidation of this was fundamental to develop an ethnographic study, which allowed us to through participant observation to survey two traditional dishes of the village and three in the Quilombo, of these, two have the same characteristics and different preparation methods, and are commonly consumed in festive seasons are recognized as traditional foods by the two communities.
\end{abstract}

Keywords: Traditional communities. Tradition.Traditional foods.Indigenous. Quilombolas.

\section{INTRODUÇÃO}

Os Povos Indígenas e as Comunidades Tradicionais enquanto grupos culturalmente diferenciados e que se reconhecem como tais, os quais possuem formas próprias de organização social, ocupam e usam territórios e recursos naturais como condição para sua reprodução cultural, social, religiosa, ancestral e econômica, utilizando conhecimentos, inovações e práticas gerados e transmitidos pela tradição, conforme define o Decreto Federal $n^{\circ}$ 6040/2007.

Essas comunidades são frutos representativos da coletividade de uma memória e cultura propriamente singular, que buscam antes de tudo serem reconhecidas pelo seu modo de vida e de reprodução social, econômica e forma de organização territorial. Como explica Oliveira (2011) são justamente esses elementos 
CE.

que as identificam como tais e fortalece a identidade coletiva, numa busca pela auto-identificação e luta pelos seus direitos, preservação da sua culturalidade e etnicidade. Para isso o Governo Federal em 2007 instituiu a Política Nacional de Desenvolvimento Sustentável de Povos e Comunidades Tradicionais (PNPCT) ${ }^{1}$ que apresenta meios sustentáveis de condição de vida, além de assegurar o exercício dos direitos individuais e coletivos desses grupos em situações de ameaça à sua integridade.

É importante ter um conhecimento amplo sobre a temática em questão, pois os povos tradicionais possuem um vasto conhecimento sobre a natureza e uma rica cultura que fora adquirido ao longo de várias gerações. Dessa forma será apresentada nesse artigo a comunidade indígena da aldeia Kanindé de Aratuba e os quilombolas da Serra do Evaristo em Baturité; ambos no estado do Ceará, entre relatos será mostrado um pouco das suas histórias e seus princípios alimentares. A pesquisa fundamenta-se em estudos voltados para comunidades tradicionais, seus saberes locais e alimentos com tradição, os quais proporcionam a soberania alimentar desses grupos sociais. Vale destacar que entende por soberania alimentar como o direito de todos ao acesso regular e permanente a alimentos de qualidade, em quantidade suficiente, sem comprometer o acesso a outras necessidades essenciais, respeitando os costumes desses povos (MALUF, 2007).

Nesse contexto, tem-se como objetivo geral mostrar como se expressa a cultura alimentar, as variações e as ligações dos preparos de cada comunidade e os saberes advindos desses povos. Os objetivos específicos apresentam-se nos registros dos preparos, resgate

\footnotetext{
${ }^{1}$ Art. $1^{\mathrm{o}}$. XIV - a preservação dos direitos culturais, o exercício de práticas comunitárias, a memória cultural e a identidade racial e étnica. Art. 3. ${ }^{\circ}$ São objetivos específicos da PNPCT: I - garantir aos povos e comunidades tradicionais seus territórios, e o acesso aos recursos naturais que tradicionalmente utilizam para sua reprodução física, cultural e econômica; V - garantir e valorizar as formas tradicionais de educação e fortalecer processos dialógicos como contribuição ao desenvolvimento próprio de cada povo e comunidade garantindo a participação e controle social tanto nos processos de formação educativos formais quanto nos não-formais; VI - reconhecer com celeridade, a autoidentificação dos povos e comunidades tradicionais, de modo que possam ter acesso pleno aos seus direitos civis individuais e coletivos; VII - garantir aos povos e comunidades tradicionais o acesso aos serviços de saúde de qualidade e adequados às suas características socioculturais, suas necessidades e demandas, com ênfase nas concepções e práticas da medicina tradicional; $\mathrm{X}$ garantir o acesso às políticas públicas sociais e a participação de representantes dos povos e comunidades tradicionais nas instâncias de controle social; XI - garantir nos programas e ações de inclusão social recortes diferenciados voltados especificamente para os povos e comunidades tradicionais; NETO, J.S. Direito dos Povos e Comunidades no Brasil: declarações, convenções internacionais e dispositivos jurídicos definidores de uma Politica Nacional. Manaus: UEA, 2007. 224 p.
}

da memória em forma narrativa, conhecimento de saberes locais que se revelam pelas falas dos entrevistados suas vivências e saberes. "Os saberes locais emergem dos lugares, um conceito socioespacial que se refere às identidades espaciais, ao sentimento de pertencimento construído nas relações cotidianas entre sujeito e espaço", (PIDNER, 2011, p. 5-6). Além disso, retratar as experiências do "vivido" ou "vivência", tendo em vista responder a questão: O que se mantém de alimentos tradicionais nessas duas comunidades, uma vez que a alimentação tem se modificado não apenas nas cidades, mas também no campo?

Tal levantamento e análise possibilitou um resgate do fazer dessas comidas que muito se perdeu no tempo, seja pela disseminação dos produtos industrializados, fato fortalecido pela mídia; ou mesmo pela dificuldade em encontrar os alimentos nesses espaços sociais.

\section{MATERIAIS E MÉTODOS}

$\mathrm{O}$ artigo é fruto de uma pesquisa intitulada "A Geografia dos alimentos tradicionais dos povos e comunidades do Maciço de Baturité: um estudo sobre os Índios Kanindé- Aratuba e os Quilombolas da Serra do Evaristo- Baturité - CE"; viabilizado pelo Núcleo de Estudo Afro-brasileiros e Indígenas (NEABI) do Instituto Federal de Educação, Ciência e Tecnologia do Ceará (IFCE- Campus Baturité).

A fundamentação teórica que conduziu a uma análise e entendimento da temática, foi pautada em autores como Little (2010) e Pidner (2011), este reforçam a questão dos saberes das comunidades tradicionais e como elas de auto-reconhecem; Zuin e Zuin (2008) discutem sobre a abordagem da produção de alimentos tradicionais e Salgado (2007) se faz importante por fomentar as questões de povos indígenas, segurança alimentar indígena e etnográfica.

Pautou-se ainda no método etnográfico com abordagem qualitativa. Nesse método nota-se uma estreita ligação entre o mundo objetivo e a subjetividade dos sujeitos e neste tipo de pesquisa os números ou dados estatísticos não são necessários como afirma o autor Oliveira (2011), com ênfase nos fatores nos estudo realizado por meio da observação in loco, coleta de depoimentos com valorização da memória e da identidade. Deste modo foram realizados trabalhos de campo no período de Julho a Setembro de 2014 e Dezembro a Abril de 2015, primeiramente foi realizada na comunidade Kanindé para encontros, reuniões e rodas de conversas com as comunidades a exemplo das lideranças autoreconhecidas como indígenas e quilombolas. Onde foram efetuadas entrevistas semi- estruturadas, buscando fazer o levantamento dos preparos de alimentos considerados 
CE.

tradicionais. As entrevistas são importantes meios de investigação social, por ser de caráter verbal e profissional onde se tem um contato direto com o entrevistado (LAKATOS; MARCONI, 2013). A efetivação dos registros aconteceu através de áudios transcritos, diálogos com os mais antigos da comunidade quilombola e as esposas dos líderes dos Kanindé, assim como as fotografias obtidas ao decorrer da pesquisa onde possibilitam que o objeto de estudo seja recuperado e expresso em forma de narrativa visual 2

Para compreensão dos processos descritos sobre as comunidades foram levantados dados documentais encontrados também em revistas, site da Fundação Nacional do Índio (FUNAI) 3 e no blog da comunidade Kanindé que auxiliaram na análise populacional e histórica da aldeia entre outros materias,como livros e cartilhas encontrados nas próprias comunidades.

\section{COMUNIDADES TRADICIONAIS: $O$ OB- JETO DE ESTUDO E SEU MODO DE VIDA}

\subsection{INDÍGENAS DE ARATUBA (ALDEIA KANINDÉ)}

A comunidade Kanindé pertencente ao município de Aratuba, localizada a $130 \mathrm{~km}$ da capital, Fortaleza, apresenta uma população de aproximadamente 641 pessoas, distribuídas em 185 famílias e 148 residências. Muitas famílias vivem exclusivamente da agricultura, outras alternam esta atividade com ocupações diversas, destacando os pequenos comércios. Outra atividade significativa na comunidade diz respeito confecção de bijuterias, realizada pelas mulheres que contribuem para o sustento familiar. A aldeia se divide em duas partes, os Fernandes e a Balança.

Os Fernandes são divididos em 16 localidades configurando-se em: Fernandes, Quebra faca, Régio, Jucazeiro, Chapada do vento, Trapiá, João Murim, Arame, Rajado, Gia, Camas de vara, Saco da onça, Mapinguim, Catolé, chapada do vento e Zalvos. Os Canindés são associados aos janduís e aos paiacus, compondo grupos que descenderiam dos tarairus. O nome dos Canindés está ligado a seu chefe histórico Canindé, mais importante na tribo dos janduís, que comandou a resistência deste povo no Século XVII, o que forçou o rei de Portugal à assinatura de um tratado de paz em 1692, tratado este que foi posteriormente descumprido pelos portugueses. Seus descendentes ficaram desde então

\footnotetext{
2"Um fragmento de vida, reminiscências de lugares, pessoas, tempo passado e presente, palavras trocadas, uma atmosfera de cheiros, cores, sabores, sons: um tecido frágil que tende a se desfazer se chegarmos perto demais e cuja consistência é a fluidez" (GONÇALVES, 2013 apud CAUQUELIN, 2008, p. 2).

${ }^{3}$ Fundação Nacional do Índio- FUNAI disponível em: <http://www.funai.gov.br/> acesso em: 23 de Maio de 2015.
}

conhecidos como Canindés em referência ao histórico líder e à ancestralidade.

Os Canindés têm por tradição oral serem originários da área que compreende o atual município de Mombaça, tendo percorrido junto aos seus parentes Jenipapos-Canindé trajeto pelas margens do rio Curu, passando por Quixadá entre os rios Quixeramobim e Banabuiú, até chegar às suas atuais terras. A história dos Canindés é marcada desde tempos remotos por uma série de deslocamentos forçados. Entretanto, conseguiu os Canindés manter laços de parentesco entre as duas comunidades que compõem o grupo entre o sertão central e a Serra de Baturité 4.

Hoje, para os Índios Kanindé de Aratuba, a Escola de Ensino Fundamental e Médio Manuel Francisco dos Santos, fundada em 2000 e direcionada por Elenilsom Gomes dos Santos, se tornou o seu principal instrumento de mobilização social, que promove ações de intercâmbios entre as comunidades (Fernandes e Balança), mobiliza a comunidade através dos alunos disseminando a cultura e as tradições dos índios Kanindé de Aratuba e criando parcerias a exemplo do Instituo Federal de Educação, Ciência e Tecnologia do CearáCampus de Baturité e a Universidade Federal do Ceará (UFC), por meio do Laboratório de Estudos Agrários e Territoriais (LEAT) e Laboratório de Cartografia (LABOCART).

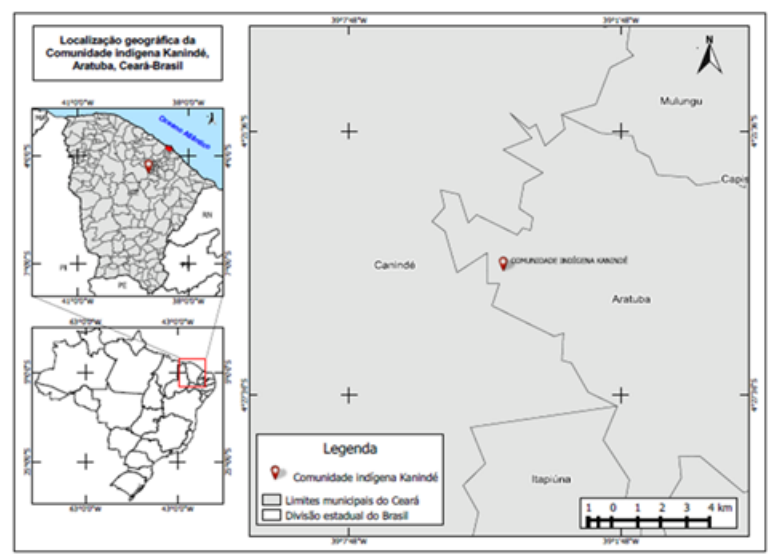

Figura 1: Mapa de localização da aldeia Kanidé-Aratuba - CE. Fonte: Laboratório de Cartografia (LABOCART - UFC) (2014).

\footnotetext{
${ }^{4}$ SOUSA, Alexandre Magno. Soberania Alimentar: Os Alimentos Tradicionais da Comunidade Indígena Kanindé de Aratuba-CEARÁ. p. 01- 11, nov. 2014.
} 
CE.

\subsection{Quilombolas da Serra do Evaristo}

A comunidade autoreconhecida como remanescentes de quilombo encontra-se localizada no município de Baturité- CE no topo da Serra do Evaristo, estando apenas $11 \mathrm{~km}$ do centro da cidade de Baturité a $100 \mathrm{~km}$ da capital cearense. Com sua história e modo de vida fundamentada na sua origem de ancestralidade negra, a população contabilizada atualmente é de aproximadamente 560 habitantes distribuídas em torno de 135 famílias que vivem principalmente da agricultura familiar.

O nome da Serra se originou de uma possível relação com a tribo indígena que antes habitava estas terras, provavelmente um índio ou cacique, considerado como um guerreiro que lutou pela comunidade e abrigou os primeiros negros refugiados por conta do processo de escravidão que acabaram chegando à comunidade. Nesse sentido Oliveira (2011, p. 7) afirma que "as comunidades remanescentes de quilombo são criações históricas e sociais, não devem ser definidas por fatores biológicos ou raciais, já que os quilombos não eram compostos apenas por negros, mas por índios, mestiços e brancos". De acordo com informações obtidas durante a pesquisa descobriu-se que a comunidade foi fundada por cinco principais famílias, que com o passar do tempo formaram o povoado, para alguns moradores isso sustenta a hipótese de que as terras foram herança familiar vindo de possíveis formações de quilombos.

A comunidade apresenta traços de cultura africana nitidamente respeitada, refletidas em sua forma de organização e modo de vida. A historicidade do local é um registro da memória da população mais antiga, uma digna representação narrativa repassadas nos encontros em família e conversas com moradores mais antigos. A dança de São Gonçalo é mais uma das expressões culturais e religiosas ativas no local. Essa é dançada por várias mulheres e alguns homens ao som de instrumentos musicais, devido às promessas que tenham sido atendidas pelo santo.

Outro fator de suma importância são os alimentos presentes no local, esses que são considerados tradicionais pela comunidade e que compõem a mesa de suas famílias; tais alimentos fazem parte de uma considerável atividade de subsistência, segundo Canesqui (1988) o alimento como estratégia de subsistência requer de uma força de trabalho revertido para uma sobrevivência familiar.

\section{TRADIÇÃO}

De acordo com o seu sentido etimológico a palavra vem do termo latino traditio ou tradire que significa "Passar

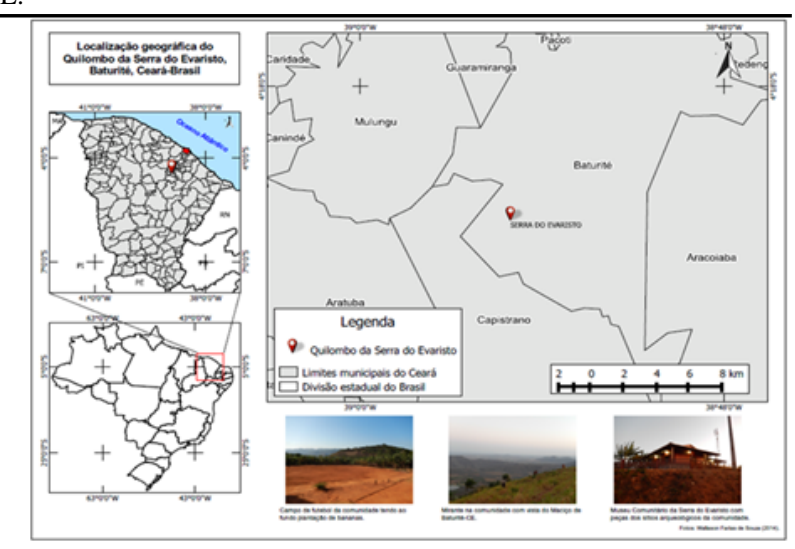

Figura 2: Mapa de localização da comunidade quilombola Fonte: Laboratório de Cartografia (LABOCART - UFC) (2014).

a diante" ou "Transmitir". A tradição é algo deixado como segmento cultural para uma comunidade ou formação de sociedade, é a transmissão de saberes, costumes, práticas, crenças e lendas. Para que uma comunidade seja tradicional é necessário que seus costumes e vivências propriamente ditos, estejam fundamentadas em costumes e memórias de seus antecedentes para que os elementos perpassados façam parte da sua cultura e modo de sobrevivência. Little (2010) afirma que o modo como surge as "tradições" está na construção de uma memória coletiva a partir do passado.

A princípio é visível que o conceito é bem difuso quando visto a realidade. Isso porque o significado e até a associação da palavra não nos remete ao passado e sim a algo do presente, uma espécie de museu vivo. Ou ainda pode-se destacar a tradição viva baseada nos mesmos princípios e práticas onde a insistência em manter os saberes culturais é bem forte, representa a sobrevivência de um povo que se preocupa em assegurar que os conhecimentos e experiências sejam repassados e cultivados pelos seus descendentes, para que os mesmos participem e deem continuidade a essa participação e preservação de experiências, é desse intercâmbio contínuo que se resume a vida desse povo. Mas também há outro viés desse conceito, o de que a tradição pode ser mantida deixando de estabelecer uma barreira intransponível e se tornando permeável ao tempo, às novas práticas, técnicas e adoção de outros elementos trazidos pelo novo tempo.

A verdade é que a manutenção das práticas de sempre ou a incorporação de elementos culturais e tecnológicos, bem como o emprego de novas técnicas, depende do interesse desses Povos Tradicionais, que ponderam o que convém preservar das práticas vernaculares e o que, das práticas e/ou instrumentos do cotidiano da sociedade, 
convém incorporar.[OLIVEIRA 2011] p. 3)

Portanto a tradição pode ter seu significado pleno enraizado no passado para orientar a vivência de hoje, de amanhã e possuir uma nova dimensão de continuação do saber com ou sem adoção de outros métodos agregados a sua identidade. Costa (2010) 5 destaca em um breve resumo sobre a obra 'Mundo em descontrole' do autor Anthony Giddens como ele aborda a questão da tradição explicando como elas são necessárias em uma sociedade para dar continuidade à vida social. No entanto ele propõe que a tradição seja defendida e perpetuada de uma maneira não tradicional, o que se torna possível a partir das trocas culturais entre demais comunidades.

Os indígenas Kanindé de Aratuba se enquadram no aspecto de preservação, onde mantêm em suas práticas subsidiadas a sobrevivência alimentar, técnicas primárias de caça e outras fontes alimentares; os quilombolas a religião e a manutenção da identidade alimentar, já que a mesma sofre com a problemática por falta de terras e diversidade alimentar, devido ás demasiadas plantações de bananeiras, além da adoção de novos métodos que proporcionaram praticidade aos preparos e a alimentação em geral.

\begin{abstract}
Eu considero como tradição aquilo que eles (os mais idosos) vão levando à frente, coisas que aprenderam com os mais antigos, então a tradição nossa aqui ela tá muito ligada à vida religiosa das pessoas [...] ligada ao mundo do trabalho, as festas de São José [...] As pessoas vão repassando isso de pai para filho só que a gente nota que aos poucos as pessoas tão perdendo né? (Alfredo Rafael.C, 47 anos, morador da comunidade quilombola, 2015).
\end{abstract}

A noção das variações como aparece à tradição é importante para entender de forma explícita como estão configuradas as comunidades tradicionais supracitadas, sua associação á alimentação também é um elemento significativo, pois nos relatos é possível compreender como determinados preparos sustentam a identidade alimentar desses povos e como a sociedade moderna pautada na globalização tem refletido em sua cultura.

\section{VOZES DO SABER}

Os saberes produzidos e vivenciados pelos integrantes das comunidades tradicionais são conhecimentos adquiridos com o passar do tempo, sem comprovações de vínculo com o científico, no entanto, algumas experiências feitas pelos moradores mais antigos nos mostram

\footnotetext{
${ }^{5}$ GIDDENS, Anthony. Mundo em Descontrole: o que a globalização está fazendo de nós.3ed. Rio de Janeiro: Record, 2003. Por COSTA, M.B. F. 2011.
}

a amplitude de seus conhecimentos empíricos. Devido a isso têm surgido diversas linhas de estudos sobre os saberes desses povos, muitos deles interligados a etnociência 6 , ou melhor, etnografia do conhecimento que busca cada vez mais contribuir com os estudos voltados para esses povos, como os estudos feitos sobre os índios Kanindé a exemplo a dissertação de Alexandre Oliveira Gomes (2012) intitulada "Aquilo é coisa de índio: objetos, memória e etnicidade entre os Kanindé do Ceará"7 7

A aproximação com essas comunidades permite dar visibilidade a esses conhecimentos locais, que diversas vezes são desvalorizados pela ciência moderna que expropria as vozes dos produtores do saber. Nesse contexto, acredita-se que a reafirmação dos saberes locais presentes, é uma forma de elevar os principais sujeitos que dão vida a narrativa do saber, além de valorizar o seu modo de vida e suas expectativas sobre o mundo. Dessa forma denomina-se nesse texto os conhecimentos vividos e produzidos pelos moradores dessas comunidades, como saberes locais ou como qualifica Pidner (2011) saberes populares, não científicos, saberes hegemônicos e saberes autóctones.

Entre trabalhos de campo e conversas com os moradores da comunidade quilombola descobriu-se que alguns homens que trabalhavam com agricultura há décadas, tinham métodos designados como experiências, para prever se o inverno seria bom para plantio, seu Alfredo Rafael. C. 47 anos, um dos entrevistados revela como isso acontece na sua fala:

\begin{abstract}
[...] Muitas coisas eles fazem, eu não sei bem as datas, mas têm os dias que eles fazem a experiência da pedra de sal, botar a pedra de sal (em um lugar ou deposito) e se no outro dia ela amanhecer molhada, eles prever um inverno bom, são coisas que agente considera como tradição [...] As pessoas mais idosas elas sabem, e aquilo ali tá na mente, tão gravados e elas não esquecem né? (Alfredo Rafael. C, 47 anos morador da comunidade quilombola, 2015).
\end{abstract}

Para Vansina (2010) esse tipo de conhecimento são tradições orais, elocuções- chaves que possibilitam a preservação da "sabedoria dos ancestrais" algo que possa ser transmitido verbalmente para as gerações futuras. Deste modo é notório pela fala do entrevistado

\footnotetext{
${ }^{6}$ Significa o estudo dos sistemas e métodos de conhecimento dos diversos povos e culturas. Aulete Digital disponível em: "As etnociências partem da linguística para estudar os saberes das populações humanas sobre os processos naturais, tentando descobrir a lógica subjacente ao conhecimento humano do mundo natural, as taxonomias e classificações totalizadoras". (DIEGUES; ARRUDA 2000).

${ }^{7}$ GOMES, Alexandre Oliveira. Aquilo é uma coisa de índio: objetos, memória e etnicidade entre os Kanindé do Ceará. Dissertação de Mestrado, Programa de Pós-Graduação em Antropologia.UFPE,2012.
} 
CE.

como o saber desses moradores antigos permanecem como narrativa na comunidade. Assim pode-se afirmar que é uma sabedoria coloquial independente se a prática tenha desaparecido ao decorrer do tempo. É algo que advém do vínculo parental, dos diálogos estabelecidos que aparecem para as novas gerações como a ciência do povo antigo.

$$
\begin{aligned}
& \text { Os saberes locais revelam os detalhes do cotidiano, o uni- } \\
& \text { verso de experiências vivido nos lugares, a transpiração } \\
& \text { do dia-a-dia. Vulgar e prático. Costumeiro e habitual. } \\
& \text { Comum e coletivo. Os saberes locais correm pelas veias } \\
& \text { do sujeito, pulsam o coração, irrigam a mente. Sujeitos } \\
& \text { são intérpretes do mundo, são autores e leitores dos sabe- } \\
& \text { res locais. Os sujeitos são feitos de saberes e os saberes } \\
& \text { são feitos de sujeito.(PIDNER 2011 p. 5) }
\end{aligned}
$$

Na aldeia Kanindé esses conhecimentos estão também ligados à questão alimentar, pois eles ainda incluem em suas práticas a caça e a pesca, algumas dessas questões partem de uma relação com mitos, lendas folclóricas que tornaram-se crendices ou superstições para a população local. Isso é algo que não é restrito só a eles, vem desde o inicio da civilização humana, porém cada lugar tem seu modo de contar ou lidar com as situações que são sempre de caráter defensivo, tentado evitar algum mal. Em um dos diálogos com moradores da aldeia foi possível ouvir algumas dessas histórias que levaram o ouvinte a despertar a curiosidade e imaginar como acontece.

\begin{abstract}
[...] A caipora que ainda existe muito aqui ainda que ela também é quem cuida das caça, ela é a dona das caça e a gente tem muita fé nela e ela a gente quando vai pro mato a gente tem um momento que a gente conversa com ela pra ela também botar as caça pra gente por que é ela quem cuida das caça ela é a dona das caça, a caipora é um... ela é um fantasma do mato, encantado que ninguém vê, mas ela mostra tudo naquele momento. No dia que ela quer que a gente não pegue nada ela arma desarma os quixótodim e não pega nada não. Ai tem a história do fumo também, que a caipora gosta muito de fumo. E a gente levando ele e botando na cabeça de um toco caba você vai e o fumo não tá mais lá não. (Cicero Pereira,63 anos, morador da aldeia Kanindé, 2014).
\end{abstract}

As vozes que narram essas histórias e vivencias fazem parte da produção da memória coletiva que vem sendo perpassada entre pais e filhos, avós e netos. É, portanto, uma história individual que passa a agregar outros indivíduos ao decorrer do tempo. Assim, [...] "A voz de um sujeito carrega as vozes de outros tantos sujeitos. As vozes se expandem e se proliferam, encontram outras vozes que as recriam, recriando saberes" (PIDNER, 2011, p. 8).

\section{OS SABORES TRADICIONAIS}

Os alimentos são reflexos dessa memória coletiva, onde os pais transmitem os conhecimentos para os filhos e, assim, tem sido possível identificar-se elaborações que se mantém no tempo e no espaço. Deste modo, segundo Zuin e Zuin (2008) são alimentos que se propagam no tempo, ligados a uma definição e características de um grupo social, ou seja, fazem parte do seu dia a dia, são esses que estão presentes nos encontros familiares e nos festejos da comunidade.

Denominados também como produtos com história, os alimentos tradicionais, são aqueles que possuem origens e raízes arraigadas na cultura alimentar desses povos. Tais produtos são considerados como matéria prima particular de cada grupo, porém assemelham-se desde o plantio ao preparo de um prato. Os alimentos são considerados tradicionais porque resistiram ao tempo, adquiriram histórias, foram repassados num encontro estabelecido entre laços familiares que revelaram o saber e a experiência; com isso foi ganhando novas características, novos métodos de manejo, novos ingredientes no fazer. No entanto essas mudanças decorrentes não impediram que suas histórias fossem recontadas e refeitas.

Durante as pesquisas realizadas nas duas comunidades, foram realizadas entrevistas com as mulheres que preparam os pratos tradicionais, onde através destas foi possível identificar os alimentos que faziam parte de cada cultura. Diante disso foi acompanhado e registrado o modo de fazer de cada prato. Na aldeia o mungunzá salgado e o pirão de fava são considerados pratos típicos pelos moradores; no quilombo foram o mungunzá salgado, o doce de mamão e a cocada. Ambas as comunidades qualificam o mungunzá salgado como um forte alimento que expressa os valores da sua cultura, um prato reconhecido pelos povos indígenas e quilombolas que perpassa por gerações. Uma das entrevistadas revela uma assertiva quando fala: "O mungunzá é aprovado pela maioria das pessoas que moram aqui, já é o costume deles desde pequenos eles viam a mãe deles fazer e eles comiam e até hoje eles gostam" (Maria do Socorro. F.C, 48 anos moradora da comunidade quilombola, 2014).

Abaixo pode-se analisar por meio do Quadro 1 e Quadro 2 os componentes de cada prato local. Mostram como se configuram os cinco pratos considerados como alimentos tradicionais nas comunidades mencionadas. De acordo com as mulheres que realizaram os preparos a seleção de ingredientes são elementos simples e fáceis de serem encontrados pela região.

No Quilombo os três preparos descritos no Quadro 1 revelam a diversidade entre o doce e o salgado, o conhecimento sobre estes, foram adquiridos pelos pais, no entanto ao longo do tempo sofreram alterações pela adoção de temperos mais práticos na cozinha. 


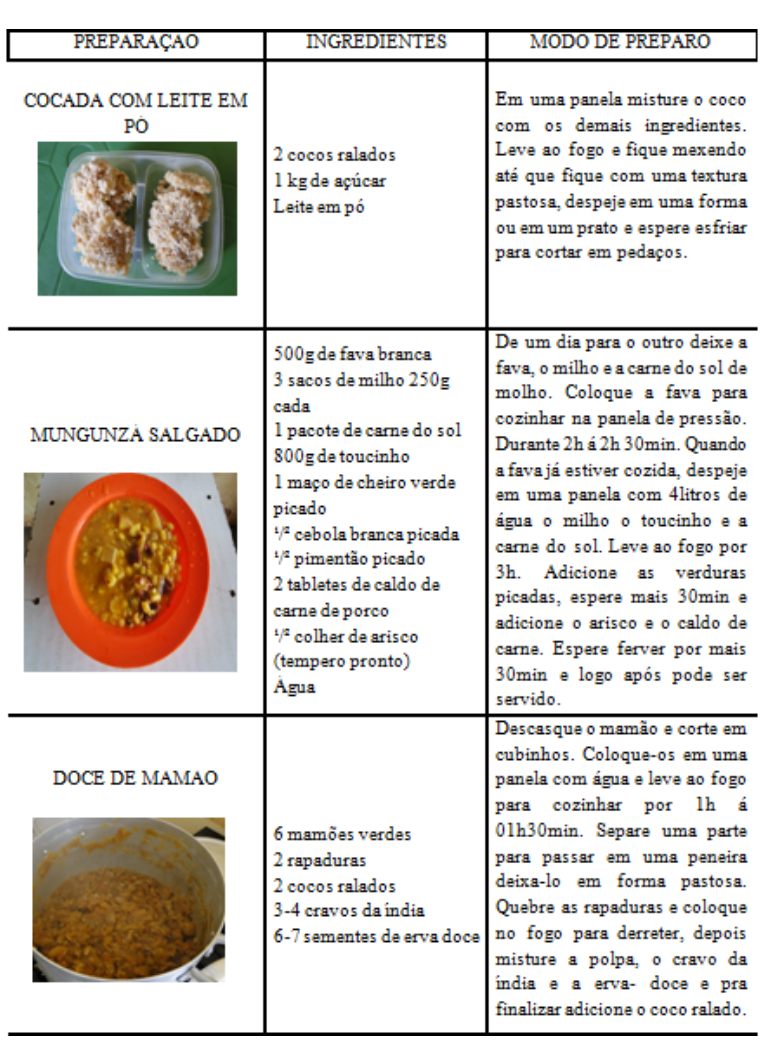

Quadro 1: Sabores do Quilombo

Fonte: Elaborado pelo Autor (2015)

\begin{tabular}{|c|c|c|}
\hline PREPARAÇÃO & INGREDIENTES & MODO DE PREPARO \\
\hline PIRÃO DE FAVA & $\begin{array}{l}\text { Fava (não a fava vermelha); } \\
\text { Jerimum } \\
\text { Mocotó. } \\
\text { Ingredientes para o pão de } \\
\text { milho: } \\
\text { Água } \\
\text { Massa de milho ou milho } \\
\text { pisado com cinzas } \\
\text { (fubango). }\end{array}$ & $\begin{array}{l}\text { Coloca a fava pra cozinhar, e } \\
\text { quando ela estiver quase } \\
\text { cozida a diciona o mocotó, o } \\
\text { jerimum e os temperos: } \\
\text { cebola, pimentão e alho. } \\
\text { Depois é só prepararo } \\
\text { cuscuz ou pão de milho, } \\
\text { esfarelar e colocar a fava, } \\
\text { depois é só misturar. }\end{array}$ \\
\hline MUNGUNZÁ SALGADO & $\begin{array}{l}\text { Fava branca que não amarga } \\
\text { Came de Charque } \\
\text { Coloral da terra } \\
\text { Milho } \\
\text { Cenoura } \\
\text { Cebolinha } \\
\text { Cheiro verde } \\
\text { Pimentão } \\
\text { Pimenta do reino } \\
\text { Cebola } \\
\text { Tomate } \\
\text { Mocotó } \\
\text { Alho e Knor }\end{array}$ & $\begin{array}{l}\text { Faz-se um pré - cozimento } \\
\text { da fava, logo após } \\
\text { acrescenta-se osingredientes } \\
\text { citadose deixa cozinhar por } \\
\text { cinco horas e está pronto o } \\
\text { mungunzá com fava. }\end{array}$ \\
\hline
\end{tabular}

Quadro 2: Sabores da Aldeia Kanidé Fonte: Elaborado pelo Autor (2015)
Na Aldeia Kanindé foi possível perceber através dos preparos contidos no Quadro 2 que eles ainda usam utensílios manuais em algumas de suas práticas, como o pilão utilizado para pisar o milho e obter a farinha e o coloral da terra feito com as sementes da planta de urucum que são encontradas em diversas partes da Aldeia.

\section{CONSIDERAÇÕES FINAIS}

Diante das informações obtidas durante a pesquisa e direcionadas em torno do texto, pode-se afirmar como é vasta a riqueza cultural dessas comunidades, sendo mostradas desde o saber aos sabores que levam a uma importante reflexão sobre a manutenção desses patrimônios materiais e imateriais; os mesmos que são bens próprios de cada sujeito, como as lendas escritas, o artesanato, as danças, entre outras produções da própria terra. Como foi discutido ao longo da pesquisa, há uma identidade alimentar em cada comunidade, havendo semelhanças entre elas. Diante das descobertas arqueológicas na Serra do Evaristo supõem-se que a mesma tenha sido habitada inicialmente por índios que abrigaram os escravos refugiados, acredita-se que sejam índios da Aldeia Kanindé.

A perspectiva em aproximar-se dos saberes relacionados aos alimentos tradicionais e suas elaborações foram atendidas, a partir do momento em que as visitas em campo se realizavam; o convívio com os moradores durante a pesquisa se materializara como de relevante importância para a identificação dos alimentos tradicionais e a viabilidade dos registros das preparações, que possibilitou entender as transformações que cada prato sofreu como a substituição da orelha de porco, pelo mocotó, o uso de outros temperos advindos de produtos industrializados e o modo de fazer que com o passar do tempo foi sendo modificado, devido a falta de alguns ingredientes locais ou á novas práticas. É importante salientar que o estudo foi baseado em alimentos que são considerados tradicionais pelos próprios moradores, onde foram identificadas através das entrevistas realizadas com as mulheres que faziam as receitas, algumas destacaram que repassam o ensinamento do prato para que ele não se perca como é o caso do mungunzá salgado, um prato típico e comumente consumido em todas as famílias das comunidades supracitadas, o mesmo é um dos que não pode faltar em festejos, encontros familiares ou em qualquer outra comemoração. No quilombo o doce de mamão e a cocada são além de fontes alimentares uma possibilidade lucrativa que ajuda na renda familiar como foi possível constatar in loco.

O modo de preparo de cada prato é particular das comunidades que os elaboram. São resquícios do co- 
CE.

nhecimento repassado pelos pais e avós que foram se moldando ao tempo e a cada espaço. É importante refletir que a preservação do conhecimento tradicional é uma forma de legitimação da cultura alimentar de cada grupo e dos alimentos ali gerados, em decorrência dos saberes locais que reafirmam seu modo de vida e formas de organização. Sem dúvidas os saberes locais de tais comunidades é algo que merece mais algum aprofundamento nas linhas de pesquisas, pois são conhecimentos empíricos que devem ser mais estudados e registrados para que as histórias não se percam no tempo e no espaço.

\section{REFERÊNCIAS}

CANESQUI, A. M. Antropologia e alimentação. Revista Saúde Pública, São Paulo, v. 22, n. 3, p. 207-215, 1988.

CRUZ, F. T. da; MENASCHE, R. Alimentos tradicionais, modos de vida e patrimônio cultural: uma reflexão a partir do queijo serrano. Ateliê Geográfico, Goiania - GO, v. 6, n. 3, p. 28-51, 2012.

DIEGUES, A. C.; ARRUDA, R. S. V. Os Saberes Tradicionais e a Biodiversidade no Brasil. São Paulo: NUPAUB- USP, MMA, 2000. 211 p.

KANINDÉ. Blog da comunidade indigena kanidé de aratuba. 2014. Disponível em: <http://escolakaninde-indio.blogspot.com.br/> Acesso em: 23 de Dez.

LAKATOS, E. M.; MARCONI, M. A. Fundamentos de metodologia científica. São Paulo: Atlas, 2013.

LIMA, M. F. F. de. Comida como cultura. Revista de Ciências Sociais da UFC, Ceará, v. 40, n. 1, p. 107-111, 2009.

LITTLE, P. E. Conhecimentos tradicionais para o século xxi: etnografias da interficientificidade. SP: Annablueme, São Paulo, p. 289, 2010.

MALUF, R. S. Segurança alimentar e nutricional. RJ: Vozes, Petrópolis, p. 174, 2007.

OLIVEIRA, J. B. Comunidade remanescente de quilombo: um novo conceito. Paraíba-PB, 2011.

PIDNER, F. S. Comunidades tradicionais: os saberes locais para além das cercas da ciência moderna. In: V Simpósio Internacional de Geografia Agrária. Belém-PA: Anais do V SINGA, 2011. 